
\title{
BResarch Soute \\ Involvement of the dorsal striatum in the processing of happy faces in Borderline Personality Disorder
}

\section{Agnes Lamers ( $\sim$ lamers.agnes@gmail.com )}

Evangelisches Klinikum Bethel gGmbH https://orcid.org/0000-0003-3751-5991

Max Toepper

Evangelisches Klinikum Bethel gGmbH

Silvia Carvalho Fernando

Evangelisches Klinikum Bethel gGmbH

Nicole Schlosser

Evangelisches Klinikum Bethel gGmbH

Eva Lenz

Justus Liebig Universitat Giessen

Friedrich Woermann

Mara Hospital Bethel

Thomas Beblo

Evangelisches Klinikum Bethel gGmbH

Martin Driessen

Evangelisches Klinikum Bethel gGmbH

\section{Research article}

Keywords: Borderline Personality Disorder, fMRI, happiness, emotion acceptance

Posted Date: March 3rd, 2020

DOl: https://doi.org/10.21203/rs.3.rs-15839/v1

License: (c) (1) This work is licensed under a Creative Commons Attribution 4.0 International License. Read Full License 


\section{Abstract}

\section{Background}

Emotion dysfunction and anhedonia are main problems in borderline personality disorder (BPD). In the present functional MRI (fMRI) study, we investigated neural activation in the processing of happy faces and its correlates with habitual emotion acceptance in patients with BPD.

\section{Methods}

22 women with BPD and 26 female healthy controls watched movie clips of happy and neutral faces during $\mathrm{fMRI}$ without any instruction of emotion regulation. To associate neural activation with habitual emotion acceptance, we included individual scores of the Emotion Acceptance Questionnaire (EAQ) as a covariate in brain data analysis.

Results

All participants showed amygdala, temporal and occipital activation in the processing of happy compared to neutral faces. Additionally, healthy controls showed activation of the hippocampus and patients with BPD showed dorso-striatal (caudate, putamen) activation in the happy compared to the neutral condition. Compared with healthy controls, patients with BPD showed significantly more caudate activation. We could not find significant correlations with the EAQ.

Conclusions

Our results indicate caudate hyperactivation in patients with BPD during the processing of happy faces. Although patients reported significantly less emotion acceptance of positive emotions, an association with neural activation was not detectable.

\section{Introduction}

Borderline Personality Disorder (BPD) is characterized by impaired emotional functioning $(1,2)$. Patients undergo intense negative emotions and report less positive affective states $(3,4)$. The lack of happiness in everyday life is problematic because positive emotions enhance resilience (5), psychosocial well-being (6) and physical health (7). According to Fredrickson and Joiner (8), frequent positive emotions broaden coping mechanisms (e.g. positive cognition) which again promote positive affect in a self-sustaining circulatory mechanism. Moreover, patients with BPD suffer from general emotional instability (1). This is problematic, because a stable experience of positive emotions in everyday life is important for overall psychological health (9).

For several authors, impaired emotion regulation is the primary emotional dysfunction in BPD patients and the main cause of further emotional symptoms in BPD (10-12). Emotion regulation is defined as a set of actions aimed at influencing which emotions we have and how we experience and express those 
emotions (13). Patients with BPD try to suppress affective arousal, not only in negative, but also in positive affective states (14). In a conceptual context, emotion suppression can be understood as a variation of emotion non-acceptance, opposing emotion acceptance $(15,16)$. It is known that attempts to suppress affective reactions lead to increased negative and decreased positive emotions in the long term (17). Emotion non-acceptance in form of suppression essentially contributes to the persistence of BPD symptoms (18) and diminishes positive experiences (19). While it is obvious that the suppression of negative emotions might be desirable, it is a matter of debate why patients hardly accept positive emotions. It has been suggested, that the attempt to avoid physiological reactions generalizes to positive emotions and that, as a result, positive emotions are perceived as being threatening (20).

FMRI research indicates that several brain areas are crucial for the processing of positive emotions: ventral and dorsal striatum (e.g. putamen, caudate), limbic areas (e.g. amygdala, hippocampus), thalamus, anterior cingulate cortex as well as prefrontal areas and fusiform gyrus (21-26). While in healthy people the processing of positive feelings was extensively investigated, studies focusing on neural activity of positive emotions in patients with BPD are rare. Koenigsberg et al. (27) found that patients with BPD showed increased activation in the temporal and inferior frontal gyrus as well as in the cerebellum, the premotor cortex and the posterior cingulate cortex compared to healthy controls when viewing positive pictures compared to a rest condition. A study by Hazlett et al. (28) found greater activation of the amygdala in patients with BPD compared to healthy controls in new and familiar emotional pictures with pleasant content compared to neutral pictures.

To our knowledge, the effects of emotion acceptance on neural activity during the processing of positive emotions in patients with BPD have not yet been investigated. A study on negative emotions showed that patients with BPD demonstrated a reduction of amygdala hyperactivation while watching emotional compared to non-emotional pictures 12 months after DBT treatment that included improvement of emotion acceptance among other emotion regulation skills (29). Moreover, our study group found that the dispositional (habitual) non-acceptance of negative emotions was correlated with more activity in caudate and putamen in patients with BPD while watching fearful vs. neutral movie scenes of human faces (30). In the latter studies, no active or instructed emotion regulation was required.

Considering the importance of positive emotions and emotion acceptance for mental health, one aim of our study was to further investigate the neural correlates of positive affect in patients with BPD. We hypothesized altered activation of striato-limbic (e.g. amygdala, caudate, hippocampus) areas as well as prefrontal and temporal brain areas and the anterior cingulate cortex in patients with BPD compared to healthy controls after experiencing emotionally positive stimuli. Accounting for the lack of studies considering habitual emotion acceptance, another aim of the study was the exploration of neural activation being associated with subjective dispositional emotion acceptance.

\section{Methods And Materials}

\section{Participants}


In the current study, we included 22 female subjects with BPD and 26 female healthy control subjects (table 1). All participants were right-handed with normal or corrected-to-normal vision. Patients were recruited at the Department of Psychiatry and Psychotherapy Evangelisches Klinikum Bethel, Germany. Healthy participants were recruited via local advertisements. Exclusion criteria for all participants were current or previous severe medical conditions (e.g. cancer) or neurological disorders (e.g. epilepsy) and incompatibilities with MRI-investigations (e.g. pregnancy). Control subjects with any lifetime psychiatric treatment were excluded. Moreover, exclusion criteria comprised changes of psychotropic medication within the last 14 days, the intake of benzodiazepines, severe actual co-morbid diagnoses (e.g. affective disorders, substance dependence or anorexia nervosa) that were not remitted for at least 6 months and DBT treatment within the last 6 months. Patients with schizophrenia were entirely excluded. In sum, 49 Patients with BPD were informed about the study but 27 had to be excluded from participation due to aforementioned conditions. Fourteen patients of our study were treated with psychotropic medication (antidepressant: $n=13$, neuroleptics: $n=6$, antiepileptics: $n=1$ ). Eleven patients with BPD hat no comorbid diagnosis. Eight patients had one and three patients had two additional diagnoses. Comorbid diagnoses were posttraumatic stress disorder $(n=8)$, social phobia $(n=3)$, specific phobia $(n=1)$, agoraphobia $(n=1)$ and obsessive-compulsive disorder $(n=1)$.

Diagnoses were made by experienced and trained clinical psychologists on the basis of the German version of the Structural Clinical Interview for DSM-IV (SCID-I) and the BPS-section of the SCID-II (SCID-II; 31). In average, patients with BPD met 6.7 out of 9 BPD criteria $(S D=1.12)$. Accordingly, the Borderline Symptom List (short version; BSL-23; 32) showed more symptoms in the BPD group than in the HC group.

Ethical approval was obtained by the Ethics Committee of the University of Muenster, Germany on January 14th, 2014. All participants gave their written informed consent prior to study participation. An allowance of $50 €$ was given to all participants.

\section{Experimental procedure}

We administered a modified version of the fearful face paradigm during fMRI (33) in order to investigate the neural correlates of the emotional response to happy faces. The original paradigm included movie sequences of fearful faces and landscapes. In our paradigm, we replaced fearful faces with happy faces and landscapes with neutral faces in order to enhance contrast specificity. This modification allowed us to link effects to the emotional valence of the presented faces while controlling for effects associated with movement perception or face recognition. Ninety-six different short movie sequences of male and female happy (happy condition) or neutral (neutral condition) faces were shown. Participants were instructed to passively watch the movie sequences; no active response was required. The experimental design is illustrated in Fig. 1.

Each of the experimental trials is composed of three phases: introduction, stimulus presentation (movie sequences) and pause. During the introduction phase, the words 'Los geht's' (english: 'Here we go') were displayed in white letters on a black screen and indicated the beginning of each trial. The introduction phase had a duration of $3200 \mathrm{~ms}$ in average with a variable jitter between $1700 \mathrm{~ms}$ and $4700 \mathrm{~ms}$ (34). 
After the introduction, movie sequences were presented with a duration of $16000 \mathrm{~ms}$. In these movie sequences, either happy (condition 'happy') or neutral faces (condition 'neutral') were shown. After the movie sequence, a pause followed, indicated by the word 'Pause' that was presented in white letters on black screen for $1700 \mathrm{~ms}$. During this pause, a white fixation cross on black background was presented for $16000 \mathrm{~ms}$. The different conditions ('happy' and 'neutral') were arranged in pseudorandomized order. Participants performed six experimental trials per condition. Additionally, participants performed two partial trials per condition (introduction and movie sequence only) to allow for the isolation of blood oxygenation level dependent (BOLD) signal-changes to the different phases of the task (35). The experimental conditions had a total duration of about 9 minutes.

\section{Clinical measures}

To relate brain activity to habitual emotion regulation, we used the German Version of the Emotion Acceptance Questionnaire (EAQ; 14). The EAQ shows very good psychometric properties with Cronbach's a between $a=.86$ and $a=.89$ and convergent validity with the Difficulties in Emotion Regulation Scale (DERS; 36) of $r=-.43$ to $r=-.65$ in clinical and non-clinical populations $(14,37)$. Two main scales are provided by the EAQ: acceptance of positive and acceptance of negative emotions. As we investigated responses to happy faces, we only included the acceptance of positive emotions scale comprising 16 items. In our sample, Cronbach's a was $a=.93$ for the healthy controls and $a=.91$ for the BPD group. The PANAS (38) was administered to assess positive and negative affectivity and includes 10 items for each condition that have to be rated on a 5-point-Likert-scale

\section{Imaging data acquisition}

All brain data were acquired in the MARA epilepsy centre (Bielefeld, Germany) with a 3-Tesla Siemens Magnetom Verio whole-body tomograph (Siemens, Erlangen, Germany) using a quantum gradient and a standard 12-channel head coil. Functional images were obtained by using a single T2-weighted gradient echo planar imaging (EPI) sequence with the following parameters: slice thickness $=4 \mathrm{~mm}(1 \mathrm{~mm}$ gap), $\mathrm{TR}=2100 \mathrm{~ms}, \mathrm{TE}=30 \mathrm{~ms}$, Flip angle $=90^{\circ}, \mathrm{FOV}=192 \times 192 \mathrm{~mm}$, matrix size $=64 \times 64$, voxel size $=3 \times 3 \times$ $4 \mathrm{~mm}$. The number of volumes was 377 , each containing 30 axial slices of the whole brain and measured in descending order parallel to the hippocampus. During scanning, participants lay in a supine position in the MR scanner. An adjustable head holder was used to restrict potential head movements. Visual stimuli were shown on a back-projection screen (1024 pixels $x 768$ pixels) near the tube end using the software "Presentation" (Neurobehavioral Systems, Albany, CA, USA). Participants watched the screen via a dualmirror that was mounted to the head coil. Before the EPI sequence, field map sequences were applied to control for magnetic field inhomogeneities. After the EPI sequence, high-resolution anatomical images were acquired using a T1-weighted, three-dimensional Magnetization Prepared Rapid Gradient Echo (MPRage) sequence (slice thickness $0.8 \mathrm{~mm}$, TR $1900 \mathrm{~ms}, \mathrm{TE}=2.5 \mathrm{~ms}$, inversion time $900 \mathrm{~ms}$, flip angle $9^{\circ}$, FOC $240 \times 240 \mathrm{~mm}$, matrix size $320 \times 320$, voxel size $0.75 \times 0.75 \times 0.75 \mathrm{~mm}, 192$ slices).

\section{Data analysis}


Behavioral data. Behavioral data were analyzed with IBM SPSS Statistics 20.0 (SPSS Inc.) using repeated measures analyses of variance (for PANAS) and two-sample t-tests (for EAQ). All levels of significance were $a \leq 0.05$ and tests were two-tailed.

Imaging data. Imaging data were analyzed using SPM12 (Statistical Parametric Mapping 12, Wellcome Department of Cognitive Neurology, London, UK; http://www.fil.ucl.ac.uk/spm). We discarded the first three images of every EPI-recording session to account for the time needed for the magnetic field to realize a steady state. The EPI data were preprocessed including field mapping, movement and slice time correction, co-registration to the individuals' structural images, 12 parameter non-linear normalization ( $3 \mathrm{~mm} \times 3 \mathrm{~mm} \times 3 \mathrm{~mm}$ ) into the Montreal Neurological Institute (MNI) reference space, and smoothing $(F W H M=9 \mathrm{~mm})$. Participants whose head movements exceeded the size of one voxel were excluded from analysis $(n=0)$. Functional imaging data were analyzed using a general linear model with five regressors, including one regressor for the movie sequences showing happy faces (condition 'happy), one regressor for the movie sequences showing neutral faces (condition 'neutral'), two regressors for the respective pauses, and one combined regressor for the introductions. Additionally, the six alignment parameters were included into the design matrix as movement regressors of no interest. Regressors were convolved using the hemodynamic response function as provided in SPM 12 and design matrices were highpass filtered (128 s).

For the identification of neural activation associated with the emotional response to happiness, activation during the movie sequences showing happy faces (condition 'happy') was contrasted to activation during the movie sequences showing neutral faces (condition 'neutral'). This contrast ('happy minus neutral') was first computed for each subject on the first level. To identify happiness-related neural networks in BPD-patients and HC-subjects as well as network differences between these groups, contrast images were then applied to second level random-effects within- and between-group analyses. To examine the impact of the level of habitual emotion acceptance on brain activation in the single experimental groups, we additionally conducted within-group analyses with the individual EAQ values (total score for acceptance of positive emotions) as covariate.

At first, all analyses in SPM were performed at whole-brain level. Whole-brain results were tested on the cluster level using a threshold of $Z>3.1$ with a minimum cluster size of $k \geq 20$ voxels and a cluster significance threshold of $\mathrm{p} \leq 0.05$ (family-wise error (FWE) corrected for multiple comparisons). Moreover, we used a region-of-interest (ROI) to examine the neural response to happiness in small brain regions (amygdala, hippocampus, thalamus, insula, striatum) that are associated with positive emotion processing (39-41). The corresponding ROI masks were taken from the automated anatomical labeling atlas (AAL; 42), which is implemented in the Wake Forest University (WFU) PickAtlas, an automated software toolbox for generating ROI masks based on the Talairach Daemon database (43-46). Contrast values from the contrast 'happiness minus neutral' were extracted using the SPM Marsbar toolbox (47) in order to further analyze these contrasts using SPSS. Contrast values represented BOLD signal changes from the 'neutral' to the 'happy' condition. 


\section{Results}

\section{Behavioral data: habitual emotion acceptance}

Patients with BPD showed significantly lower mean scores of emotion acceptance of positive emotions (EAQ) than healthy controls (table 1). According the PANAS, repeated-measures ANOVA revealed a significant main effect of time (pre-post comparison; $F_{1,46}=33.26, p<.001, \eta_{p}^{2}=.42$ ) and a significant

main effect of group $\left(F_{1,46}=10.09, p=.003, \eta_{p}^{2}=.18\right)$ but no time $x$ group interaction effect $\left(F_{1,46}=1.11\right.$, $p=.30$ ) These results indicate a reduction of positive affectivity over time in both groups. Generally, atients with BPD showed less positive affect than healthy controls.

\section{fMRI data}

For healthy controls (table 2a, Fig. 2), cluster-based whole-brain analysis identified two large clusters with activation peaks in left middle occipital gyrus and right middle temporal gyrus in the 'happy compared to the 'neutral' condition (contrast 'happy minus neutral'). Additional ROI-analyses revealed increased activation in the bilateral amygdala and the left hippocampus (table $2 b$ ).

For the patient group (table 2c, Fig. 2), cluster-based whole-brain analysis also revealed increased occipital and temporal but also increased precentral and striatal activation in the 'happy' compared to the 'neutral' condition (contrast 'happy minus neutral') within five clusters. Two clusters had activation peaks in the left middle occipital gyrus with one cluster also showing left lingual activation. One cluster showed right temporal and lingual activation. Moreover, two clusters had activation peaks in the bilateral caudate, with one cluster showing additional activation in the left putamen and left pallidum and the other cluster showing addition activation the left precentral gyrus. On a cluster level we found five clusters with activation peaks in the left middle occipital gyrus (two clusters) and the right middle temporal gyrus (one cluster), as well as within left and right caudate (two clusters). ROI-analyses additionally revealed increased activation in bilateral amygdala for the 'happy compared to the 'neutral' condition (table 2d).

Between-group comparisons revealed no significant whole-brain differences between patients with BPD and healthy controls for the contrast 'happy minus neutral'. However, ROl-analyses revealed increased activation in bilateral caudate in patients with BPD compared to healthy controls for the contrast 'happy minus neutral' (table 2e, Fig. 3). Healthy controls did not show increased activation compared to patients with BPD in any of the ROIs. In both groups, neural activation in positive compared to neutral emotions did not correlate with emotion acceptance of positive emotions.

\section{Discussion}

In the current work, we explored the neural correlates of positive emotions in patients with BPD and healthy controls. We found temporal, limbic (including the amygdala) and occipital activation in both study groups. Our main findings show that patients with BPD exhibit a hyperactivation of striatal brain areas and particularly show stronger activation in bilateral caudate than healthy controls when they 
experience positive emotions. Other than expected, the disposition to accept positive emotions did not correlate with neural activation during positive emotion processing.

We found hyperactivation of the bilateral caudate during the processing of positive emotions in patients with BPD compared to healthy controls. The caudate is crucial for planning goal-directed behavior and for the processing of reward-related information (48-50). Together with the putamen and the ventral striatum, the caudate is part of an emotional-motivational system (51). Caudate hyperactivation in our study may reflect stronger emotional arousal in patients with BPD compared to healthy controls. Patients with BPD probably experience emotional states independent of the specific emotional valence (e.g. happiness or fear) more intensively (52). Moreover, Kim and Hamann (53) found activation in the dorsal striatum (caudate and putamen) and the pallidum in healthy controls when trying to increase positive emotions compared to a simple watching condition. In contrast to Kim and Hamann (53), participants of our study were not instructed to regulate their emotional reaction. Therefore, another explanation of our findings might be a habitual attempt of patients with BPD to regulate their emotional arousal. As caudal activation was only observable in patients with BPD, healthy controls possibly experienced less needs to regulate their emotional reaction than patients with BPD. However, our correlational analysis of habitual emotion acceptance and neural activity did not show significant results. Nevertheless, patients with BPD reported less emotion acceptance of positive emotions than healthy controls which is in line with previous findings (14). As emotion acceptance was assessed using a self-report questionnaire, a negative bias in subjective recall of emotional experience in patients with BPD (54) might have exaggerated the rating of emotion non-acceptance in the patient group. It is possible that the actual emotional experience during our experiment did not differ that much between patients with BPD and healthy controls on an acceptance-related neural level but patients might have remembered EAQ-relevant everyday situations differently than healthy controls.

Although the group-difference in hippocampal activity did not reach statistical significance, we found activation of the hippocampus in healthy controls but not in patients with BPD in the processing of positive emotions. The hippocampus is important for emotion processing and memory (55) with impaired functioning in mental disorders $(56,57)$... In a recent study, Lambert et al. $(58)$ found, that earlylife stress (e.g. violence exposure in childhood) might lead to impaired hippocampal development. Thus, missing hippocampal activity in patients with BPD when positive emotions were induced may be attributable to stressful childhood events that are often reported in patients with BPD (59).

Our findings of amygdala activation in positive emotion processing in both groups is in line with previous findings $(24,40)$. In a PET-study, Hamann et al. $(60)$ found increased activation of the left amygdala when healthy subjects processed pictures conveying positive emotions and "interesting" images without apparent emotional content (e.g. rhinoceros). The authors suggested, that activation of the amygdala might reflect a vigilant reaction rather than the experience of a particular emotion. In line with that, Phelps (61) outlined that the amygdala appears to navigate attention to relevant stimuli and that this attention is facilitated by emotional context. Becauseamygdala activation in our study occurred in both study groups without significant group differences, we could not confirm altered amygdala activation in patients with 
BPD during the processing of positive emotions. According van Zutphen et al. (62) findings of altered amygdala involvement in emotion processing in patients with BPD are rather inconsistent, resulting from methodical (e.g. fMRI acquisition settings like slice thickness) or individual (e.g. dissociation) differences. In contrast to our methodological approach, van Zutphen et al. (62) rather suggests a more liberal exploration of the amygdala with an uncorrected significance threshold of $p \leq 0.05$.

Moreover, we found activation of middle and superior occipital and temporal regions in the processing of happy faces that was also comparable in both groups. Occipitotemporal activation is associated with the perception of faces and their emotional expressions $(63,64)$ as well as with positive emotion processing (53). This indicates stronger visual perception of happy compared to neutral faces in all participants of our study. The study groups did not seem to differ in the perception of happy (facial) expressions.

In total, our study has several strengths. To make sure that confounding aspects (e.g. processing of facial attributes) were eliminated, we used stimuli (facial expressions) that only differed with respect to the emotional content. Moreover, we did not use any kind of cognitive task that could have influenced emotion processing. On the contrary, some limitations have to be discussed, too. First, some patients also suffered from other diagnoses (e.g PTSD). However, comorbid disorders are typical for patients with BPD and their exclusion would have resulted in a non-representative study group. Second, psychotropic medication may have influenced emotion processing of our patients. Third, we did not implement immediate emotional valence ratings after each stimuli presentation. However, although this might have enabled a more detailed estimation of emotion processing in our study, it might also have influenced neural activity (65). Forth, the impact of our positive emotion stimuli might not have been strong enough to elicit neural reactions that could be associated with habitual emotion acceptance. According to Garland et al. (66), positive emotions in experimental investigations should be prevailing in a considerably larger extend.

In conclusion, our investigation of neural correlates of positive emotion processing is important for the understanding of emotion experience and emotion dysregulation in patients with BPD. Our results indicate increased neural activation in dorso-striatal brain areas and the hippocampus in patients with BPD in the processing of positive emotions. Although patients reported less emotion acceptance of positive emotions in our study, the neural correlates of positive emotion (non-) acceptance did not become clear. Because positive emotions are not only pleasurable but also fulfil a function of protection against consequences of stressful experiences, the enhancement and training of positive emotion experience could be clinically relevant for the recovery of patients with BPD. Regarding this, the interaction of different emotion valances should be focused in future studies. Research needs to further assess the experiential, neural and behavioral mechanisms that underlie positive emotion processing and regulation of positive emotions in patients with BPD.

\section{Declarations}


Acknowledgements: The authors thank Violetta Swiatek for her expertise and kind help during the fMRI investigations. We also thank all participants for their willingness to take part in this study. We thank the German Research Foundation ("Deutsche Forschungsgemeinschaft", DFG) for the financial support.

Competing interests: None declared.

Contributions: M. Toepper, S. Carvalho Fernando, N. Schlosser, M. Driessen and T. Beblo designed the study. A. Lamers, S. Carvalho Fernando and F. Woermann acquired the data. A. Lamers, M. Toepper, S. Carvalho Fernando, E. Lenz and T. Beblo analyzed the data. A. Lamers and T. Beblo wrote the article. All authors reviewed the article and approved the manuscript to be published. No other individuals not listed as authors have made contributions to the paper.

Data: Data are available from the authors on request.

Ethical Approval: Ethical approval was obtained by the Ethics Committee of the University of Muenster, Germany on January $14^{\text {th }}, 2014$.

Funding: This work was financially supported by the DFG ("Deutsche Forschungsgemeinschaft", grants: BE 2536 / 9-1, TO 894 / 3-1).

\section{References}

1. Lieb K, Zanarini MC, Schmahl C, Linehan MM, Bohus M. Borderline personality disorder. The Lancet. 2004;364(9432):453 - 61.

2. Marissen MA, Arnold N, Franken IH. Anhedonia in borderline personality disorder and its relation to symptoms of impulsivity. Psychopathology. 2012;45(3):179 - 84. PubMed PMID: 22441143.

3. Shearin EN, Linehan MM. Dialectical behavior therapy for borderline personality disorder: theoretical and empirical foundations. Acta Psychiatr Scand Suppl. 1994;379:61 - 8. PubMed PMID: 8010153.

4. Reed LI, Zanarini MC. Positive affective and cognitive states in borderline personality disorder. Journal of personality disorders. 2011 Dec;25(6):851 - 62. PubMed PMID: 22217230.

5. Tugade MM, Fredrickson BL. Regulation of Positive Emotions: Emotion Regulation Strategies that Promote Resilience. Journal of Happiness Studies. 2006;8(3):311 - 33.

6. Fredrickson BL. Cultivating Positive Emotions to Optimize Health and Well-Being. Prevention \& Treatment. 2000;3.

7. Kok BE, Coffey KA, Cohn MA, Catalino LI, Vacharkulksemsuk T, Algoe SB, et al. How positive emotions build physical health: perceived positive social connections account for the upward spiral between positive emotions and vagal tone. Psychological science. 2013 Jul 01;24(7):1123-32. PubMed PMID: 23649562.

8. Fredrickson BL, Joiner T. Positive Emotions Trigger Upward Spirals toward Emotional Well-Being. Psychological science. 2002;13(2):172-5.

9. Gruber J, Kogan A, Quoidbach J, Mauss IB. Happiness is best kept stable: positive emotion variability is associated with poorer psychological health. Emotion. 2013 Feb;13(1):1-6. PubMed PMID: 23163709. 
10. Glenn CR, Klonsky ED. Emotion dysregulation as a core feature of borderline personality disorder. Journal of personality disorders. 2009 Feb;23(1):20 - 8. PubMed PMID: 19267659.

11. Gratz KL, Rosenthal MZ, Tull MT, Lejuez CW, Gunderson JG. An experimental investigation of emotion dysregulation in borderline personality disorder. Journal of abnormal psychology. 2006 Nov;115(4):850-5. PubMed PMID: 17100543.

12. Putnam KM, Silk KR. Emotion dysregulation and the development of borderline personality disorder. Development and psychopathology. 2005 Fall;17(4):899-925. PubMed PMID: 16613424.

13. Gross JJ. Emotion regulation: Affective, cognitive, and social consequences. Psychophysiology. 2002 281-291;29.

14. Beblo T, Fernando S, Kamper P, Griepenstroh J, Aschenbrenner S, Pastuszak A, et al. Increased attempts to suppress negative and positive emotions in Borderline Personality Disorder. Psychiatry research. 2013 Dec 15;210(2):505-9. PubMed PMID: 23871409.

15. Hofmann SG, Asmundson GJ. Acceptance and mindfulness-based therapy: new wave or old hat? Clinical psychology review. 2008 Jan;28(1):1-16. PubMed PMID: 17904260.

16. Campbell-Sills L, Barlow DH, Brown TA, Hofmann SG. Effects of suppression and acceptance on emotional responses of individuals with anxiety and mood disorders. Behaviour research and therapy. 2006 Sep;44(9):1251-63. PubMed PMID: 16300723.

17. Rassin E, Merckelbach H, Muris P. Paradoxical and less paradoxical effects of thought suppression: a critical review. Clinical psychology review. 2000 Nov;20(8):973 - 95. PubMed PMID: 11098396.

18. Stepp SD, Scott LN, Morse JQ, Nolf KA, Hallquist MN, Pilkonis PA. Emotion dysregulation as a maintenance factor of borderline personality disorder features. Comprehensive psychiatry. 2014 Apr;55(3):657 - 66. PubMed PMID: 24342056. Pubmed Central PMCID: 3965595.

19. Kashdan TB, Barrios V, Forsyth JP, Steger MF. Experiential avoidance as a generalized psychological vulnerability: comparisons with coping and emotion regulation strategies. Behaviour research and therapy. 2006 Sep;44(9):1301-20. PubMed PMID: 16321362.

20. Weiss NH, Gratz KL, Lavender JM. Factor Structure and Initial Validation of a Multidimensional Measure of Difficulties in the Regulation of Positive Emotions: The DERS-Positive. Behavior modification. 2015 May;39(3):431 - 53. PubMed PMID: 25576185. Pubmed Central PMCID: 4420643.

21. Phan KL, Wager T, Taylor SF, Liberzon I. Functional neuroanatomy of emotion: a meta-analysis of emotion activation studies in PET and fMRI. Neurolmage. 2002 Jun;16(2):331 - 48. PubMed PMID: 12030820.

22. Dolan RJ, Fletcher P, Morris J, Kapur N, Deaking JFW, Frith CD. Neural Activation during Covert Processing of Positive Emotional Facial Expressions. Neurolmage. 1996;4:194-200.

23. Cunningham WA, Kirkland T. The joyful, yet balanced, amygdala: moderated responses to positive but not negative stimuli in trait happiness. Social cognitive and affective neuroscience. 2014 Jun;9(6):760-6. PubMed PMID: 23563851. Pubmed Central PMCID: 4040091.

24. Mather M, Canli T, English T, Whitfield S, Wais P, Ochsner K, et al. Amygdala Responses to Amotionally Valanced Stimuli in Older and Younger Adults. Psychological science. 2004;15(4):259 - 63.

25. Lane RD, Reiman EM, Ahern GL, Schwartz GE, Davidson RJ. Neuroanatomical correlates of happiness, sadness, and disgust. The American journal of psychiatry. 1997 Jul;154(7):926 - 33. PubMed PMID: 
9210742.

26. Suardi A, Sotgiu I, Costa T, Cauda F, Rusconi M. The neural correlates of happiness: A review of PET and fMRI studies using autobiographical recall methods. Cognitive, affective \& behavioral neuroscience. 2016 Jun;16(3):383 - 92. PubMed PMID: 26912269.

27. Koenigsberg HW, Siever LJ, Lee H, Pizzarello S, New AS, Goodman M, et al. Neural correlates of emotion processing in borderline personality disorder. Psychiatry research. 2009 Jun 30;172(3):192-9. PubMed PMID: 19394205.

28. Hazlett EA, Zhang J, New AS, Zelmanova Y, Goldstein KE, Haznedar MM, et al. Potentiated amygdala response to repeated emotional pictures in borderline personality disorder. Biological psychiatry. 2012 Sep 15;72(6):448 - 56. PubMed PMID: 22560044. Pubmed Central PMCID: 3415575.

29. Goodman M, Carpenter D, Tang CY, Goldstein KE, Avedon J, Fernandez N, et al. Dialectical behavior therapy alters emotion regulation and amygdala activity in patients with borderline personality disorder. Journal of psychiatric research. 2014 Oct;57:108 - 16. PubMed PMID: 25038629. Pubmed Central PMCID: 4263347.

30. Lamers A, Toepper M, Carvalho Fernando S, Schlosser N, Bauer E, Woermann F, et al. Nonacceptance of negative emotions in women with borderline personality disorder: association with neuroactivity of the dorsal striatum. Journal of Psychiatry and Neuroscience. 2019;44(1):303 - 13.

31. Wittchen HU, Zaudig M, Fydrich T. SKID - Strukturiertes Klinisches Interview für DSM-IV. Achse I und II. Handanweisungen. Göttingen: Hogrefe; 1997.

32. Bohus M, Kleindienst N, Limberger MF, Stieglitz RD, Domsalla M, Chapman AL, et al. The short version of the Borderline Symptom List (BSL-23): development and initial data on psychometric properties. Psychopathology. 2009;42(1):32 - 9. PubMed PMID: 19023232.

33. Schacher M, Haemmerle B, Woermann FG, Okujava M, Huber D, Grunwald T, et al. Amygdala fMRI lateralizes temporal lobe epilepsy. Neurology. 2006 Jan 10;66(1):81 - 7. PubMed PMID: 16401851. 34. Amaro E, Jr., Barker GJ. Study design in fMRI: basic principles. Brain and cognition. 2006 Apr;60(3):220 - 32. PubMed PMID: 16427175.

35. Motes MA, Rypma B. Working memory component processes: isolating BOLD signal changes. Neurolmage. 2010 Jan 15;49(2):1933-41. PubMed PMID: 19732840. Pubmed Central PMCID: 2804888. 36. Gratz KL, Roemer L. Multidimensional Assessment of Emotional Regulation and Dysregulation: Development, Factor Structure, and Initial Validation of the Difficulties in Emotion Regulation Scale. Journal of Psychopathology and Behavioral Assessment. 2004;26(1):41-54.

37. Beblo T, Scheulen C, Carvalho Fernando S, Griepenstroh J, Aschenbrenner S, Rodewald K, et al. Psychometrische Analyse eines neuen Fragebogens zur Erfassung der Akzeptanz von unangenehmen und angenehmen Gefühlen (FrAGe). Zeitschrift für Psychiatrie, Psychologie und Psychotherapie. 2011;59(2):133 - 11.

38. Krohne HW, Egloff B, Kohlmann C-W, Tausch A. Untersuchungen mit einer deutschen Version der "Positive and Negative Affect Schedule" (PANAS). Diagnostica. 1996;42(2):139 - 56.

39. Goldin PR, McRae K, Ramel W, Gross JJ. The neural bases of emotion regulation: reappraisal and suppression of negative emotion. Biological psychiatry. 2008 Mar 15;63(6):577 - 86. PubMed PMID: 17888411. Pubmed Central PMCID: 2483789. 
40. Fusar-Poli P, Placentino A, Carletti F, Landi P, Allen P, Surguladze S, et al. Functional atlas of emotional faces processing: a voxel-based meta-analysis of 105 functional magnetic resonance imaging studies. Journal of psychiatry \& neuroscience: JPN. 2009 Nov;34(6):418 - 32. PubMed PMID: 19949718. Pubmed Central PMCID: 2783433.

41. Banks SJ, Eddy KT, Angstadt M, Nathan PJ, Phan KL. Amygdala-frontal connectivity during emotion regulation. Social cognitive and affective neuroscience. 2007 Dec;2(4):303 - 12. PubMed PMID:

18985136. Pubmed Central PMCID: 2566753.

42. Tzourio-Mazoyer N, Landeau B, Papathanassiou D, Crivello F, Etard O, Delcroix N, et al. Automated anatomical labeling of activations in SPM using a macroscopic anatomical parcellation of the MNI MRI single-subject brain. Neurolmage. 2002 Jan;15(1):273 - 89. PubMed PMID: 11771995.

43. Lancaster JL, Rainey LH, Summerlin JL, Freitas CS, Fox PT, Evans AC, et al. Automated labeling of the human brain: a preliminary report on the development and evaluation of a forward-transform method. Human brain mapping. 1997;5(4):238 - 42. PubMed PMID: 20408222. Pubmed Central PMCID: 2860189. 44. Lancaster JL, Woldorff MG, Parsons LM, Liotti M, Freitas C, Rainey L, et al. Automated Talairach Atlas labels for functional brain mapping. Human Brain Mapping. Human brain mapping. 2000;10(3):120 - 31 . 45. Maldjian JA, Laurienti PJ, Kraft RA, Burdette JH. An automated method for neuroanatomic and cytoarchitectonic atlas-based interrogation of fMRI data sets. Neurolmage. 2003;19:1233-9.

46. Talairach J, Tournoux P. Co-planar stereotactic atlas of the human brain: 3-Dimensional proportional system: an approach to cerebral imaging. Stuttgart: Thieme; 1998.

47. Brett M, Anton JL, Valabregue R, Poline JB. Region of interest analysis using an SPM toolbox. Paper presented at the 8th International Conference on Functional Mapping of the Human Brain, June 2-6, 2002, Sendai, Japan. Available on http://marsbar.sourceforge.net/. 2002.

48. Balleine BW, Delgado MR, Hikosaka O. The role of the dorsal striatum in reward and decision-making. The Journal of neuroscience : the official journal of the Society for Neuroscience. 2007 Aug 1;27(31):8161-5. PubMed PMID: 17670959.

49. Grahn JA, Parkinson JA, Owen AM. The cognitive functions of the caudate nucleus. Progress in neurobiology. 2008 Nov;86(3):141 - 55. PubMed PMID: 18824075.

50. Tricomi EM, Delgado MR, Fiez JA. Modulation of Caudate Activity by Action Contingency. Neuron. 2004;41:281 - 92.

51. Loonen AJ, Ivanova SA. Circuits regulating pleasure and happiness in major depression. Medical hypotheses. 2016 Feb;87:14-21. PubMed PMID: 26826634.

52. Linehan MM. Cognitive-Behavioral Treatment of Borderline Personality Disorder. New York: Guildford Press; 1993.

53. Kim SH, Hamann S. Neural correlates of positive and negative emotion regulation. Journal of cognitive neuroscience. 2007 May;19(5):776 - 98. PubMed PMID: 17488204.

54. Ebner-Priemer UW, Kuo J, Welch SS, Thielgen T, Witte S, Bohus M, et al. A valence-dependent groupspecific recall bias of retrospective self-reports: a study of borderline personality disorder in everyday life. The Journal of nervous and mental disease. 2006 Oct;194(10):774-9. PubMed PMID: 17041290. 55. Critchley H, Daly E, Phillips M, Brammer M, Bullmore E, Williams S, et al. Explicit and implicit neural mechanisms for processing of social information from facial expressions: a functional magnetic 
resonance imaging study. Human brain mapping. 2000 Feb;9(2):93-105. PubMed PMID: 10680766. 56. Fu CHY, Williams SCR, Brammer MJ, Suckling J, Kim J, Cleare AJ, et al. Neural Responses to Happy Facial Expressions in Major Depression Following Antidepressent Treatment. American Journal of Psychiatry. 2003;164:599-607.

57. Phillips ML, Drevets WC, Rauch SL, Lane R. Neurobiology of emotion perception II: Implications for major psychiatric disorders. Biological psychiatry. 2003 Sep 1;54(5):515 - 28. PubMed PMID: 12946880. 58. Lambert HK, Peverill M, Sambrook KA, Rosen ML, Sheridan A, McLaughlin KA. Altered Development of Hippocampus-Dependent Associative Learning following Early-Life Adversity. Developmental cognitive neuroscience. 2019;38(100666):13.

59. Zanarini MC, Williams AA, Lewis RE, Reich RB, Vera SC, Marino MF, et al. Reported pathological childhood experiences associated with the development of borderline personality disorder. American Journal of Psychiatry. 1997;154:1101-6.

60. Hamann SB, Ely TD, Hoffmann JM, Kilts CD. ECSTASY AND AGONY: Activation of the Human Amygdala in Positive and Negative Emotion. Psychological science. 2002;13(2):135 - 41.

61. Phelps EA. Human emotion and memory: interactions of the amygdala and hippocampal complex. Current opinion in neurobiology. 2004;14:198-202.

62. van Zutphen L, Siep N, Jacob GA, Goebel R, Arntz A. Emotional sensitivity, emotion regulation and impulsivity in borderline personality disorder: A critical review of fMRI studies. Neuroscience and biobehavioral reviews. 2015 Apr;51:64-76. PubMed PMID: 25616185.

63. Posamentier MT, Abdi H. Processing Faces and Facial Expressions. Neuropsychology review. 2003;11(3):113 - 43.

64. Rossion B, Hanseeuw B, Dricot L. Defining face perception areas in the human brain: a large-scale factorial fMRI face localizer analysis. Brain and cognition. 2012 Jul;79(2):138 - 57. PubMed PMID: 22330606.

65. Taylor SF, Phan KL, Decker LR, Liberzon I. Subjective rating of emotionally salient stimuli modulates neural activity. Neurolmage. 2003 Mar;18(3):650-9. PubMed PMID: 12667842.

66. Garland EL, Fredrickson B, Kring AM, Johnson DP, Meyer PS, Penn DL. Upward spirals of positive emotions counter downward spirals of negativity: insights from the broaden-and-build theory and affective neuroscience on the treatment of emotion dysfunctions and deficits in psychopathology. Clinical psychology review. 2010 Nov;30(7):849 - 64. PubMed PMID: 20363063. Pubmed Central PMCID: 2908186.

\section{List Of Abbreviations}

BPD Borderline Personality Disorder

DBT Dialectical Behavioral Therapy

fMRI Functional magnetic resonance imaging

FWE Family-wise-error 
PTSD Posttraumatic stress disorder

ROI Region-of-interest

\section{Tables}

Due to technical limitations, Tables 1-2 are provided in the Supplementary Files section.

\section{Figures}

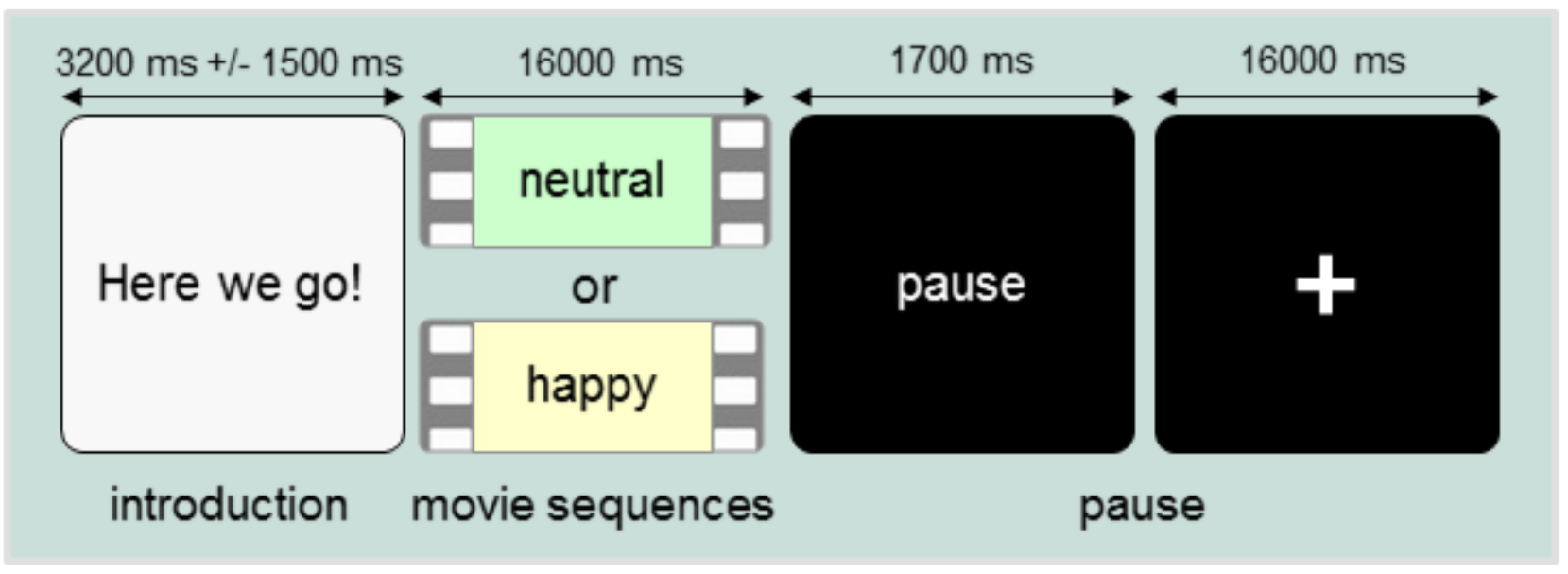

Figure 1

Illustration of the experimental design including timing of regressors.

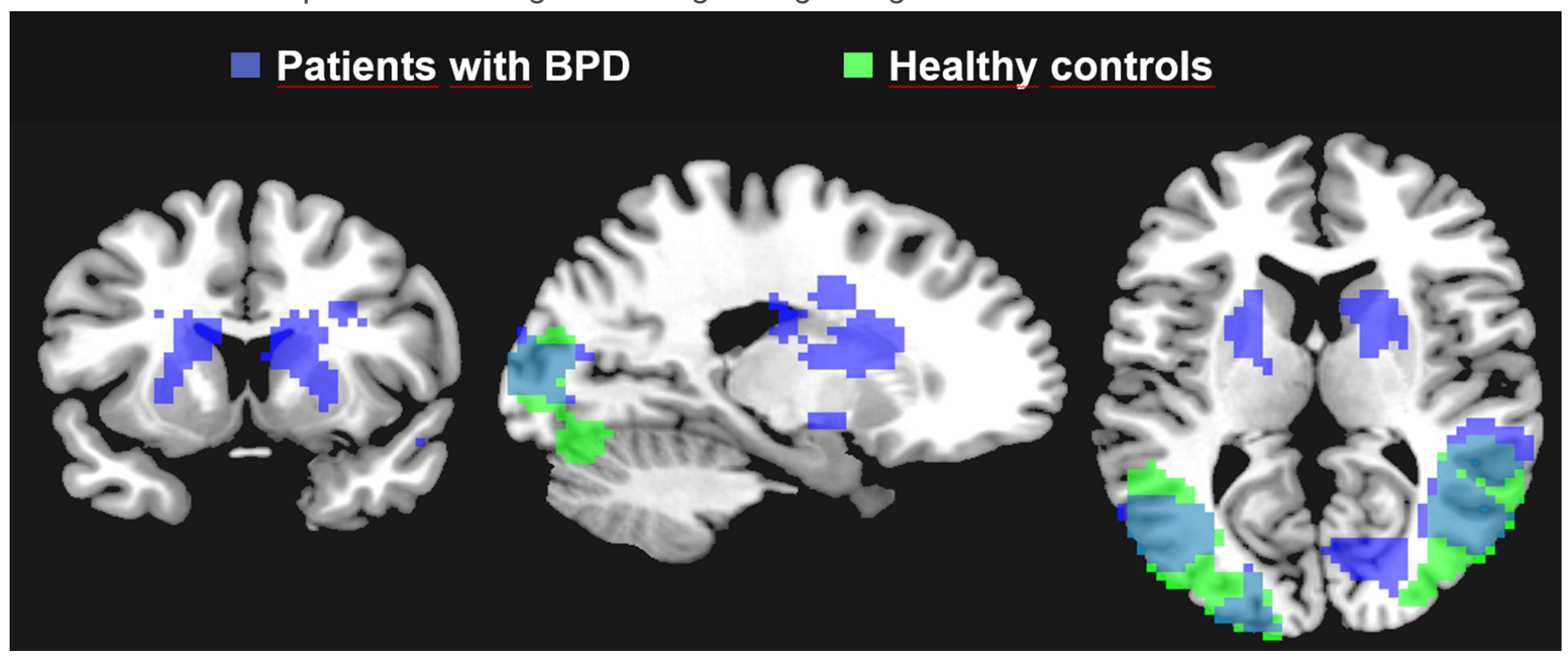




\section{Figure 2}

Whole-brain activation in patients with BPD (blue) and healthy controls (green). Displayed are the wholebrain results of within-group cluster-level analyses with cluster significance thresholds of $p \leq 0.05$ (family-wise error (FWE) corrected for multiple comparisons) and minimum cluster sizes of 20 voxels.

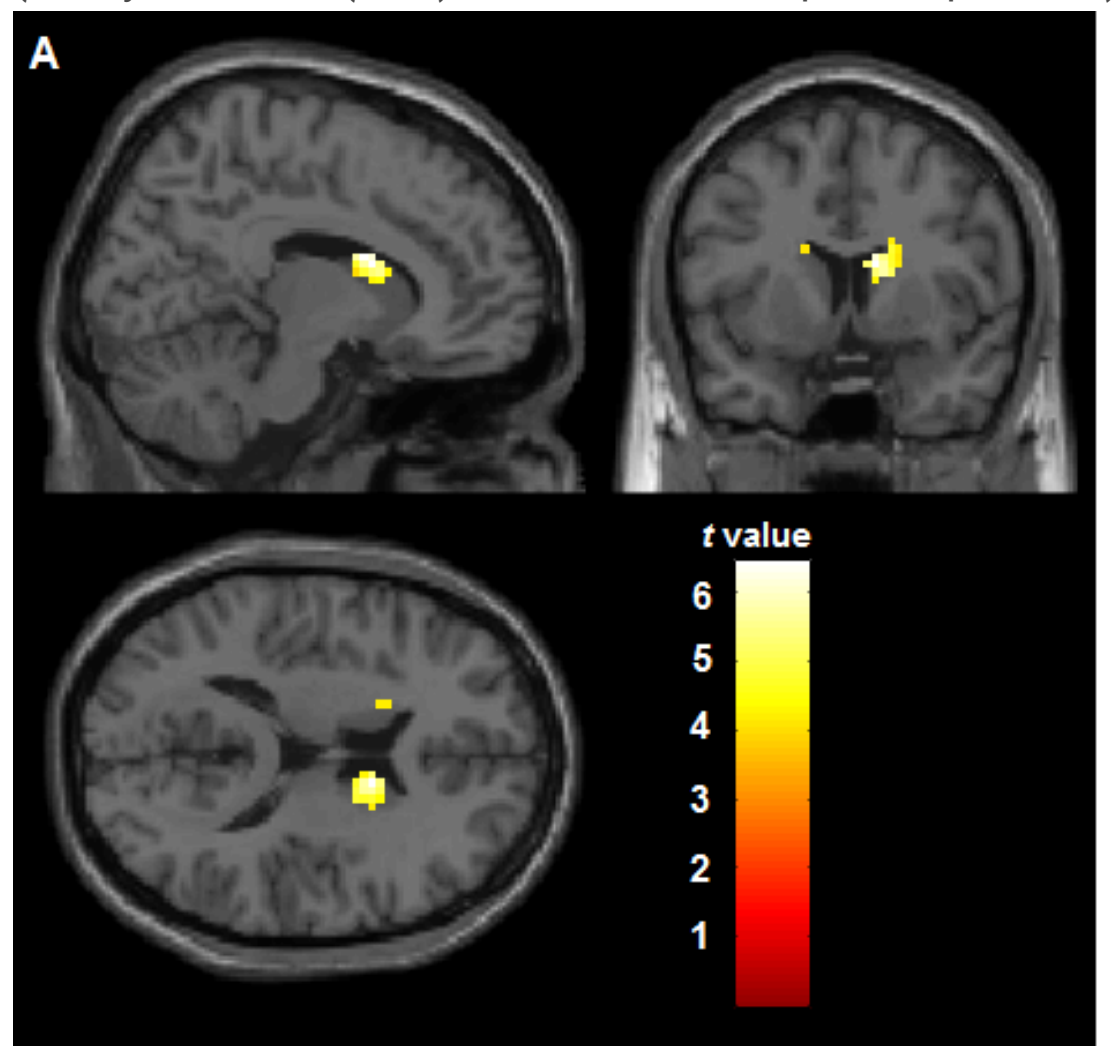

B $\approx \mathrm{BPD}=$ Healthy controls

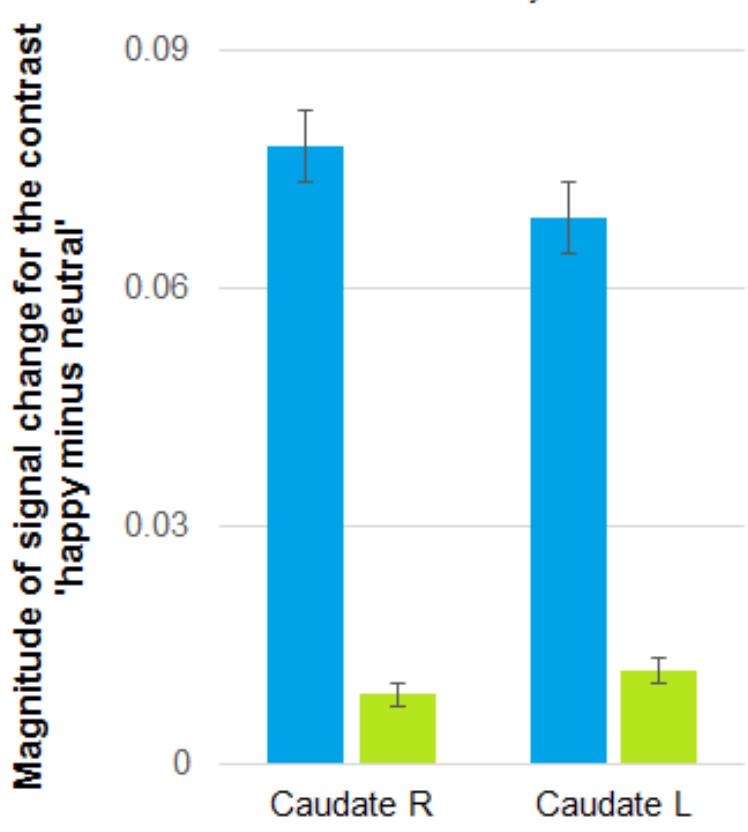

Study groups and bilateral caudate

\section{Figure 3}

Illustration of bilateral caudate activation in (A) patients with BPD and (B) mean signal change with standard errors of the mean in response to happy faces (contrast 'happy minus neutral') in patients with $B P D$ and healthy controls. Displayed are the results of region-of-interest analyses with a significance threshold of $p<.005$, FWE-corrected for multiple comparisons and minimum size of $k=5$ voxels. Abbreviations: $\mathrm{L}=$ left hemisphere, $\mathrm{R}=$ right hemisphere, $\mathrm{BPD}=$ Borderline Personality Disorder

\section{Supplementary Files}

This is a list of supplementary files associated with this preprint. Click to download.

- Tables.docx 